(sodium) enter the posterior segment of the cavity of the eye (in large measure, at any rate) by way of the ciliary body.

All the thiocyanate determinations described in this paper were carried out by Mr. A. M. Woodin.

\title{
REFERENCES
}

ALDRIDGE, W. N. (1945).-Analyst, 69, 262.

BÁRÁNY, E. H. and DAvson, H. (1948).-Brit. J. Ophthal., 32, 313.

Benham, G. H., Duke-Elder, W. S. and Hodgson, T. (1937).-J. Physiol., $92,355$.

Davson, H. and DukE-Elder, W. S. (1948). I Ibid., 107, 141.

Davson, H., Duke-Elder, W. S. and Maurice, D. M. (1948).-Ibid., 107, Proc. Physiol. Soc.

Davson, H., Duke-Elder, W. S., Maurice, D. M., Ross, E. J. and Woodin, A M. (1949).-Ibid., in press.

DUKE-ELDER, W. S. and DAVSON, H. (1949)-.Brit. J. Ophthal , 33, 21.

Kinsey, V. E. and Grant, M. (1942).-J. Gen. Physiol., 26, 131.

Maurice, D. M. (1948).-J. Physiol., 107, Proc. Physiol. Soc.

Palm (1948).-Acta Ophthal. Kbh., Suppl. 32.

\section{DISEASES OF THE EYE IN RELATION TO DENTAL SURGERY*}

BY

\section{J. H. DOggaRt}

LONDON

THE current fashion of labelling diseases " allergic" has to some extent diverted attention from focal sepsis. Nevertheless that controversy is still alive, and it would be safe to predict widely varying estimates if any twelve ophthalmologists were invited to answer the question: "What percentage of the ocular disease in your practice is due to unhealthy teeth?" There are, of course, many other organs and tissues on which attention has been riveted by people seeking to explain inflammatory lesions of the eye. The vermiform appendix, the colon, the prostate gland, the skin and the tonsils have all been singled out for blame, and that list might be greatly extended.

In all the mass of literature dealing with ocular disease of supposedly dental origin, one feature has escaped comment, so far as I have been able to ascertain. I refer to the curious assumption that infective traffic between the teeth and the eyes must be one-way. When will some champion take up the cudgels on behalf of these much-maligned gomphoses? Such a man might begin by

* Lecture delivered in the Royal College of Surgeons, England, on March 7, 1948 Received for publication, March 14, 1949. 
proclaiming his disbelief in dental iridocyclitis, and then, carrying the war into the enemy's camp, he would doubtless marshall statistics whereby ocular lesions could be indicted as a source of parodontal disease. The main weakness of this doctrine would be that it could hardly be carried to its logical end, because total extraction .is so infinitely more drastic a policy when dealing with eyes than with teeth. No such objection, however, would arise if the blame were put upon the ocular adnexa, which consist of the eyelids and lacrimal apparatus. When once an observer had convinced himself that among the convolutions of the Meibomian glands lurked organisms more dangerous than those harboured by any other focus, he would soon be assembling cases in which treatment applied to the eyelids had been followed by dramatic amelioration of the dental state. He might even persuade his patients that they should go to bed with teeth uncleaned rather than neglect their lid-massage.

It may be well, however, to postpone this question of focal sepsis until we have considered some of the instances in which teeth and eyes are fellow-victims of (1) abnormal development, (2) trauma, (3) diseases of other organs and tissues, and (4) toxic hazards.

\section{A. Associatri Ocular and Dental Lesions}

1. Developmental defects of the eyes and teeth are inevitable whenever there is widespread malformation of the head and face, but fortunately most of the resulting monsters are stillborn. More important from the practical standpoint are cases in which infantile lamellar cataract is associated with hypoplasia of the teeth. Theoretically these allied signs might be attributable to some defect in the germ-plasm - that is to say, they might be hereditary in the strictest sense; but most people interpret them as the effect of unfavourable intra-uterine influences, such as toxins derived from micro-organisms, or poisonous substances in the mother's food. Maternal diet can be the vehicle of damage not only through its noxious contents, but also by reason of deficiency. There might, for instance, be a shortage of certain essential amino-acids, vitamins or metals. Adequate calcium content is one well-recognised need during pregnancy, and the relationship of that element with the parathyroids is bound up with the influence of the latter upon the skeletal system. Parathyroid defect is closely linked with tetany and rickets, and the dental changes chiefly implicate the first molars together with the central and lateral incisors.

2. Trauma. One of the greatest therapeutic triumphs of modern times is the treatment of severe facial injuries, especially those accompanied by fractúre of the upper-jaw. During the recent war 
I visited the maxillo-facial units at Hill End, Park Prewett and East Grinstead, and also had the opportunity to see their successful end-results coming back into active service. Many a man hurtled against a wall in motor-cycle crashes would have been condemned to frightful disfigurement and enduring diplopia, had it not been for the skill of dental and plastic surgeons promptly administered. The ingenious devices whereby traction was applied to reinforce the action of splints after early reduction of those impacted maxillary fractures moved me to admiration, and there must be many medical men whose respect for the dental profession was enhanced by wartime contacts.

In the early stages of severe facial injury ophthalmic examination is needed with a view to ascertaining whether any immediate eye treatment is necessary, but thorough inspection is often impossible until swelling of the eyelids has abated. Later on the patient may require orthoptic and operative treatment for double vision due to weakness of one or more of the extra-ocular muscles, but spontaneous recovery from diplopia often ensues within a few weeks, if early manipulation by a dental expert has succeeded in restoring the alignment of the inferior orbital margin.

One possible result of maxillary trauma is an extension of sepsis from the teeth to the eyes, but the routes whereby infective material may travel will be considered later. Another possibility to be borne in mind is that ocular damage may be occasioned by a violent dental extraction. In this connection the myopic retina is particularly vulnerable. When we consider that the jolt of a starting train has been known to provoke retinal detachment, and that large haemorrhages may become evident on the surface of the fundus immediately after a sneeze, it is not surprising that similar havoc may accrue when jaws are wrenched against the resistance of muscular spasm. This last-mentioned state of affairs is apt to arise when a strong man undergoes incomplete dosage with nitrous oxide.

Before we leave the subject of trauma, it may be interesting to recall that a few of the dental surgeons attached to maxillo-facial units in the recent world war became expert in the construction of artificial eyes. In one instance I can testify to such skill on the part of a Service dentist, to whom I referred a number of cases needing prostheses. So far I have failed to trace any evidence of reciprocal virtuosity on the part of an ophthalmologist, and I doubt whether many of you would be inclined to delegate the building of your patients' dentures to an eye doctor.

3. Diseases of other organs and tissues. (a) Endocrine dyscrasia. Reference has already been made to the close relationship of the parathyroids with calcium metabolism, and we know 
that other members of the endocrine orchestra can exert a profound influence upon dental and ocular welfare before and after birth. Thus the skeletal changes associated with dyspituitarism can interfere with the alignment of teeth, and the victim may also exhibit defects of the fields of vision due to pressure of the gland upon the optic chiasma or adjacent portions of the visual pathway.

The eruption of teeth is delayed in cretins, and further impairment is entailed by pressure from the heavy, splayed-out tongue typical of this disease, which in its turn is caused by hypoplasia of the thyroid gland. Further evidence that secretion from this gland affects the dental state is provided by the administration of thyroxin to experimental animals. Eruption of the incisors is thereby accelerated.

One disease that has often been found in association with widespread endocrine disturbance is keratoconjunctivitis sicca, a condition arising in middle life, and predominantly affecting women. It is characterised by sensations of dryness and grittiness of the eyes. Examination usually reveals irregularity of the corneal epithelium, together with small whitish strands of irregularly proliferating cells attaiched to the surface of the cornea. Absence of or diminution in the tears must be held partly responsible for the symptoms, but deprivation of the mucus normally secreted by small glands in the conjunctiva probably counts more. From the dental surgeon's standpoint the main importance of keratoconjunctivitis sicca is that similar desiccation usually occurs in the victim's mouth. Therefore she may become incapable of tolerating her dentures for more than a few minutes at a time.

(b) Bone disease. A number of bone diseases possess joint interest for dental and ophthalmic surgeons. Acute osteomyelitis of the upper jaw is one example which may arise in early infancy. Most people are agreed that ethmoidal suppuration is the commonest cause of orbital cellulitis among infants, but maxillary osteomyelitis, with or without preceding trauma to the mouth, should always be borne in mind as a possibility. Some of the reported cases have been fatal, but successful results have recently been claimed for penicillin therapy. Swelling and induration of the cheek on the affected side is a conspicuous sign, the temperature is high, and the infant usually looks very ill. When an abscess forms, it may point along the gum-line, on the palate, in the nose, or through the lower eyelid. Proptosis and restriction of ocular movement on the affected side are prominent features until the pus is absorbed or evacuated.

In osteogenesis imperfecta we find blue sclerotics associated with abnormal fragility of the bones, so that fracture of the lower jaw may arise from a relatively slight blow. The upper and lower jaw 
may both be implicated in Schüller-Christian xanthomatosis, a disease which may produce proptosis of the eyeballs in early childhood. Slight fever, secondary anaemia, and diabetes insipidus due to hypopituitarism are other items in the clinical picture, and the diagnosis is clinched by radiography of the skull, the flat bones displaying punched-out areas of rarefaction. Albers-Schönberg's disease tends to run in families, and consists of diffuse osteosclerosis. One of its characteristic results is bilateral optic atrophy due to encroachment of the new-formed bone upon the optic canai. Delayed dentition and early caries are also noted, and occasionally osteomyelitis of one or both jaws supervenes. In oxycephaly the small size of the maxilla may interfere with dental development by crowding the teeth together. Delayed dentition is also a feature of hereditary cleido-cranial dysostosis, a disease in which defective ossification of the skull-vault lends to depression of the orbital roofs, and that in its turn produces exophthalmia.

Two bone diseases of later onset are worthy of mention. Leontiasis ossea is particularly apt to induce hideous deformity, because the two sides of the face are seldom symmetrically involved. Lateral and forward displacement of one or both eyes may become evident, and vision may be curtailed by pressure upon the optic nerve in its bony canal. Similarly the teeth may sustain damage and displacement from irregular encroachment of bone in the upper and lower jaws. In advanced cases the dental state may be aggravated by hindrance to closure of the mouth. Paget's disease is a familial affection of later life, often associated with generalised arteriosclerosis. Immense thickening occurs in the long and flat bones, and $\mathrm{X}$-ray photographs in an advanced case reveal characteristic areas of adjacent absorption and calcification. In some cases the onset is exceedingly slow, and indeed this disease may stay mainly confined to one bone for many months. Probably the tibia is the commonest single bone to display Paget's type of thickening, but cases have been described in which signs were first exhibited in the maxilla. Sooner or later the orbital walls begin to thicken, and deposition of bone in the optic canal leads to progressive optic atrophy. .

Skeletal and endocrine diseases have been briefly reviewed, because they supply so many striking instances of associated dental and ocular disturbance. Other kinds of linkage might readily be assembled, but here it will suffice to stress the interdependence of organs and tissues throughout the body. Clearly the eyes and the teeth are likely to last longer in people blessed with a sound cardiovascular system, and yet the finest heart and blood-vessels in the world cannot keep these organs healthy unless their nervous connections are intact-because all nerves are in a real sense trophic. 
Nor can the nervous and circulatory structures function well, unless every essential item of diet is supplied in appropriate quantity. Thus the problem of causation in an apparently simple lesion may be complex beyond the bounds of imagination. Whatever facts may be elicited by clinicians working in close co-operation with dietetic experts, pathologists, radiologists and other specially trained helpers, we cannot explain every aspect of disease, because the mode of response to identical noxious stimuli may be largely conditioned by genetical factors impossible of assessment.

4. Toxic hazards. A few examples will serve to show how the eyes and teeth share susceptibility to a number of poisons. Lead can play havoc with the optic nerve and the jaws, but improved plumbing together with preventive industrial measures have almost eliminated this former scourge. Necrosis of the orbit and jaws from phosphorus is also rare to-day. Indeed so much knowledge has accumulated concerning the injurious by-products of mines and factories, that important chemical lesions seldom arise unless workers are unintentionally exposed to some new organic compound, the pharmacological effect of which is not yet appreciated. Many volumes have been written upon the deleterious effects of nicotine upon the eyes and teeth, and we cannot expect to find unanimity of opinion upon this question for many a year to come. Few would deny that excessive smoking injures the buccal mucous membrane, and incidentally the teeth, but wide individual variations in tolerance make one man's moderation another man's excess. Tobacco amblyopia is a real threat to heavy smokers in later life, and necessitates complete abstinence from smoking, but other factors besides tobacco play a part in its development.

\section{B. The Teeth as a Source of Ocular Infection}

It is abundantly clear that some disease-processes can spread from the teeth to the eyes, but wide disagreement exists concerning the proportion of dental infection compared with that from other sources. Theoretically dental disease could be communicated to the eye by direct extension through bone and other connective tissue, or along the ramifications of nerves, or via the veins and lymphatic vessels. Toxins might enter the blood-stream direct from diseased teeth and afterwards find their way into the ocular arteries; or the noxious material might travel indirectly, being absorbed into the blood-stream via the alimentary canal. Nor would it seem impossible for dental toxins to reach the inferior meatus of the nose, whence they can travel up the tear-passages into the conjunctival sac. Probably all or most of these pathways have been traversed by infective material, but dissemination by the blood-stream is 
generally. regarded as the most important, except in cases which plainly show direct spread.

Among the conditions which ophthalmologists have regarded as due to dental disease are orbital cellulitis, dacryocystitis, blepharitis and other inflammatory disorders of the eyelids, conjunctivitis, episcleritis, keratitis with or without ulceration, iridocyclitis, choroido-retinitis, venous thrombosis, cataract and lesions of the optic nerve. In this connection particular stress has been laid upon iridocyclitis, and the reasons are not far to seek. Cases of iridocyctitis exhibit astonishing variations in severity and duration, and incidentally, of course, in their apparent response to treatment. Some show slight initial changes, but keep on recurring until the eye is ruined. Others severely affected at the outset clear up rapidly, and then go on for years without further trouble. It follows therefore that any treatment will appear to produce miraculous results in, a certain number of cases. Enthusiasts naturally resent being told that they have mistaken mere sequence for a cause-and-effect relationship, but such reminders are wholesome and necessary. In dealing with so variable a disease as iridocyclitis, we have to look askance at alleged therapeutic triumphs until the method in question has proved effective in a long series of carefully followed-up cases.

Now the theory of focal infection, so long as it is firmly upheld, can be advanced as a coherent explanation for nearly all kinds of endocular inflammation, and positively disproved in hardly any instance. Let us imagine a case of iridocyclitis being examined in consultation with a colleague firmly convinced that teeth are nothing but fountains of sepsis. No clinical evidence of dental disease can be found. Then he points out that a healthy-looking tooth may be likened to a whited sepulchre. X-ray photographs are now prepared, but fail to reveal any abnormality. Our friend now proceeds to quote authority for his belief that radiographically negative teeth are by no means incapable of spreading disease elsewhere in the body. Thus he persuades the patient to part with his teeth, and one of three things happens :

(a) The eye recovers. That clinches the argument.

(b) The eye gets worse, but that goes to prove how wise it was to insist upon extraction. Exacerbation analogous to a Herxheimer reaction is readily interpreted as the effect of an extra dose of toxin. flung into the circulation while the teeth were being dislodged.

(c) No change is noted in the eye. Therefore the offending teeth must have set up a secondary focus of infection before the patient had finally decided to part with them. Probably the prostate is now to blame, though admittedly palpation reveals no abnormality of that organ. Yes, but chronic prostatitis may drag on for 
years without producing any localising signs or symptoms. Prostatectomy is now performed. Still the iridocyclitis grumbles on, because [sic] the original focus has impaired the patient's power of resistance, and he is now susceptible to the action of lesser toxins, which he would have taken in his stride had his defences not been undermined by those teeth.

Let me repeat that such a zealot cannot be decisively confuted at any stage in his argument, and my reason for setting-out that grim sequence of events is that I have often heard people argue on those lines. With very little modification the same kind of reasoning can be adduced to prove that any particular disease is an outburst of allergy-whatever that may be.

It would appear, however, that the concept of dental infection as a paramount factor in the production of intra-ocular disease has lost ground. Several research workers have failed to repeat the earlier work on apical infection, and it has been suggested that oral contamination would explain many disquieting statistics about - the prevalence of streptococci in the teeth. It has also been shown that radiolucent areas around dental roots are not necessarily a sign of disease, and more and more people have come to believe that teeth should be treated on their own merits-or demerits, as the case may be. Was it not Don Quixote who said: "A diamond is not as precious as a tooth." My own attitude towards the relation of dental with ocular disease can be summarised as follows :

(1) Harmful substances can certainly pass from the teeth to the eyes, and possibly in the reverse direction.

(2) I do not believe that the teeth are mainly to blame in more than a small minority of the cases of ocular disease.

(3) The causation of disease is infinitely more complex than most people realised three or four decades ago, when the doctrine of focal sepsis was approaching the peak of its popularity.

In fairness to the dental surgeon, it should be pointed out that the indiscriminate slaughter of teeth as a measure of desperation in cases not responding to other forms of treatment has nearly always been at the instigation of medical men. Consider rheumatoid arthritis and recurrent iridocyclitis, which have several important features in common. Both are productive of much pain and disability. In each of these diseases the cause is complex and imperfectly known, so that the stage is set for the enthusiast whose attention is disproportionately directed to one aspect of the problem. Some cases of iridocyclitis display features which an experienced clinician can recognise as pathognomonic or at least strongly suggestive of syphilis, gonorrhoea, tubercle and various other diseases. Corroboration is in many instances supplied by the 
manifestations of a similar pathology elsewhere in the body. Nevertheless it remains true that, in any large series of people suffering from iridocyclitis, there will be a considerable percentage to whose origin there is no clue, unless the observer happens to be a fanatic. The proportion of unsolved cases is greater among female than among male victims, largely because typical gonococcal iridocyclitis seldom arises in women.

\section{Cq-operation Between Dental and Ophthalmic Surgeons}

Theoretically an eye capable of resisting certain toxins entering the circulation from unhealthy teeth might be rendered vulnerable in consequence of trauma. Therefore many ophthalmologists, unless the case is urgent, deliberately refrain from performing an intra-ocular operation until any necessary dental treatment has been completed. - Others maintain that this precaution makes no appreciable difference to the prognosis, and some go so far as to say that post-operative complications are rendered more likely by the flood of toxic matter dislodged by dental extraction, and they point out that removal of any considerable number of teeth is often followed by general lowering of a patient's power of resistance. Perhaps the best solution is to treat every case as a separate problem, but certainly it seems a reasonable precaution in all except urgent cases, to postpone intra-ocular surgery pending dental treatment, if gross oral sepsis comes to light. It would also seem wise, in cases requiring multiple tooth-extraction, to arrange for a few weeks' convalescence before the eye operation is performed.

There are many other fields for fruitful co-operation between these two branches of surgery. During the World War of 1939-45 important pieces of research had to be shelved in favour of activities calculated to produce immediăte results, and specialised training was perforce curtailed. There is, however, another side to the picture. Under the impact of war, opportunities arose for tryingout new methods of treatment on a large scale, and the maxillo-facial units, of which mention has already been made, enabled ophthalmic and dental surgeons to realise how many of their problems overlap. Now it seems certain that technique will continue to grow more specialised in every branch of medicine and surgery, and all such improvements count as progress. Neverthless they sound a note of warning. Each successive refinement in technique is a potential barrier or path of divergence between one kind of specialist and another, so that we must be vigilant to keep an eye upon the borderline territory-yes, and to maintain a firm bite upon joint problems. Long ago Saint Lucia was singled out as the patroness of the eye, and a similar rôle was granted in the realm of dentistry to Saint 
Apollonia, but some of the ancient English people looked upon Saint Lucia as the luminary responsible for both sets of organs. Let me conclude with the hope that this primitive belief was of good augury, and that it will serve to emphasise the significance of our eye-teeth.

\title{
LITERATURE
}

BEnEDICT, W. L. (1941).-Hyperostosis of the orbit. Amer. J. Ophthal., 24, 1005.

Clifton, W. M., Frank, A. A. and FreEman, S. (1938).--Osteopetrosis (Marble bones). Amer. J. Dis. Child., 56, 1020.

Dessoff, J. (1934).-Blue sclerotics, fragile bones and deafness. Arch. of Ophthal., 12, 60 .

FREY, W. G. (1937).-Paget's disease of the skull. Ibid., 18, 477.

GuYton, J. B. and Woods, A. C. (1941).-Etiology of uveitis. Ibid., 26, 983.

KRAVITZ, D. (1946).- Infections and reflex disorders of the eye from dental infection. Amer. J. Ophthal., 29, 1135.

ROPER-HALL, H. T. (1.942). - Oral sepsis in relation to ophthalmology. Brit. J. Ophthal., 26, 141.

Rushton, M. A. (1948).-Advances in the treatment of oral and dental diseases. Pract., 161, 321.

SJöGREN, H. (1948).-Kerato-conjunctivitis sicca and chronic polyarthritis. Acta Med. Scand., 130, 484.

Souter, W. C. (1930).-Disorders of secretion of endocrine glands. Trans. Ophthal. Soc. U.K., 50, 69.

Wheeler, J. M. (1934).-Schüller-Christian-Hand disease (Xanthomatosis).Arch. of Ophthal., 11, 214.

WILMER, W. H. (193:).-The relation of teeth to diseases of the eye. Arch. of Ophthai., 4,.453.

$\because$

\section{CONCENTRATION IN THE AQUEOUS OF VARIOUS SULPHONAMIDES AFTER SYSTEMIC ADMINISTRATION*}

\author{
BY \\ ARNOLD SORSBY
}

LONDON

ThE earlier experimental studies of Bellows and Chinn (1939 and 1941), Pinkoff (1939), Meyer, Bloch and Chamberlain (1941), Liebman and Newman (1941), and Scheie and Souders (1941), have established that sulphanilamide and sulphapyridine penetrate readily into the interior of the eye on oral administration, whilst sulphathiazole has a poor penetration: The penetration of sulphadiazine was found to be high (Scheie and Souders, 1941; Liebman and Newman, 1941). There do not appear to be any studies on the newer sulphonamides such as sulphamezathine and sulphamerazine. For clinical purposes sulphanilamide and sulphapyridine can be ignored as they are no longer widely used owing to their relative toxicity. In practice the choice to-day is

* Dedicated to Professor J. Meller. 